\title{
The Nucleotide Sequence of Staphylococcus aureus Plasmid pT48 Conferring Inducible Macrolide-Lincosamide-Streptogramin B Resistance and Comparison with Similar Plasmids Expressing Constitutive Resistance
}

\author{
By I. CATCHPOLE, C. THOMAS, $\dagger$ A. DAVIES AND K. G. H. DYKE* \\ Microbiology Unit, Department of Biochemistry, University of Oxford, South Parks Road, \\ Oxford OXI $3 Q U, U K$
}

(Received 6 June 1987)

\begin{abstract}
The complete nucleotide sequence of a naturally occurring Staphylococcus aureus plasmid, pT48 (from $S$. aureus strain T48), has been determined. The 2475 bp plasmid confers inducible resistance to macrolide-lincosamide-streptogramin B (MLS) type antibiotics. It is similar to the constitutive MLS resistance plasmid, pNE131, from Staphylococcus epidermidis and shows homology with $S$. aureus plasmids pSN2 and pE194. It contains a palA structure homologous to that on $S$. aureus plasmid pT181. The open reading frame, ORF B, within the pSN2 homologous region has a frameshifted C-terminus, relative to pNE131, resulting in a smaller, 158 amino acid putative polypeptide. The $\mathrm{pE} 194$ homologous region has the ermC resistance determinant and retains the leader region, deleted in pNE131, required for inducible expression of an adenine methylase.

Another naturally occurring $S$. aureus strain, J74, shows constitutive resistance to erythromycin and contains a small plasmid, pJ74, which is similar to pNE131 but with a different deletion in the leader sequence. The results are consistent with the translational attenuation model for erm C expression.
\end{abstract}

\section{INTRODUCTION}

Staphylococcus aureus strains that are resistant to erythromycin are also often resistant to other macrolides, lincosamides and streptogramin B (MLS) antibiotics (Dubnau, 1984; Weisblum, 1984). Such naturally occurring MLS resistance is also seen in a variety of other organisms: Bacillus spp. (Docherty et al., 1981; Gryczan et al., 1984; Mahler \& Halvorson, 1980), Streptococcus spp. (Horinouchi et al., 1983; Clewell, 1981) and Streptomyces spp. (Fujisawa \& Weisblum, 1981), including Streptomyces erythraeus, the producer of erythromycin. In these species, MLS resistance is mediated by specific $N^{6}, N^{6}$-dimethylation of adenine in 23S rRNA. This results in reduced ribosomal affinity for MLS antibiotics (Dubnau, 1984; Weisblum, 1984; Lai et al., 1973; Lai \& Weisblum, 1971; Skinner et al., 1983). Production of the methylase enzyme involved is often inducible by sub-inhibitory concentrations of erythromycin or the related antibiotic oleandomycin (Dubnau, 1984; Weisblum, 1984; Murphy, 1985; Horinouchi et al., 1983; Gryczan et al., 1984).

Three different determinants involved in MLS resistance have been described in Staphylococcus aureus: ermA (Murphy, 1985; Murphy et al., 1985), ermB (Novick et al., 1979; Khan \& Novick, 1980) and ermC (Horinouchi \& Weisblum, 1982). The former two genes are located on the transposons Tn554 (Murphy, 1985; Murphy et al., 1985) and Tn551 (Novick et al., 1979; Khan \& Novick, 1980) respectively, whereas ermC was first described on the $3.7 \mathrm{~kb}$

Abbreviations: MLS, macrolide-lincosamide-streptogramin B; ORF, open reading frame.

† Present address: Department of Biochemistry, University of Leicester, Leicester LE1 7RU, UK. 
plasmid pE194 (Horinouchi \& Weisblum, 1982). Expression of ermA and ermC determinants is inducible by erythromycin. Nucleotide sequence analysis and molecular studies of ermC have led to the postulation of a model for this regulation (Dubnau, 1984; Weisblum, 1984). The mechanism involved is post-transcriptional (Gryczan et al., 1980; Horinouchi \& Weisblum, 1980 ) and, by analogy to the transcriptional attenuation seen in amino acid biosynthesis genes (Kolter \& Yanofsky, 1982), is described as translational attenuation.

There have been a number of reports in the literature of small, $2.0-2.5 \mathrm{~kb}$, MLS-resistanceconferring plasmids, both in $S$. aureus and in Staphylococcus epidermidis (Bastos et al., 1980; Iordanescu \& Surdeanu, 1980; Parisi et al., 1981; Keller et al., 1983). Such plasmid-borne MLS resistance is generally constitutive, but the sequence of the plasmid pNE131 from $S$. epidermidis shows strong homology with ermC (Lampson \& Parisi, 1986a,b). pNE131 has a 1074 bp region of homology with pE194 which contains the determinant ermM, almost identical to ermC apart from a 107 bp piece, absent in the former. This results in the loss of some of the complementary base-pairing regions within the $5^{\prime}$ leader of the ermM mRNA which are critical for inducible expression of ermC (Lampson \& Parisi, 1986a; Dubnau, 1984; Weisblum, 1984). An almost identical plasmid to pNE131, found naturally in Bacillus subtilis, pIM13, has also recently been sequenced (Monod et al., 1986).

In this paper we present the complete nucleotide sequence ( $2475 \mathrm{bp}$ ) of a naturally occurring $S$. aureus plasmid, pT48. Although similar to pNE131, it retains all the complementary repeats required for the inducibility of erm $C$ expression, some of which are deleted in the $S$. epidermidis plasmid. A further $S$. aureus plasmid, pJ74, is described. This bears close homology to pNE131, but has a different mRNA leader deletion, resulting in constitutive MLS resistance. A region of pT48 homologous to the small cryptic $S$. aureus plasmid pSN2 (Khan \& Novick, 1982) is also discussed, together with features of the remainder of pT48, in relation to the replication of this and other small $S$. aureus plasmids (Gruss et al., 1987; Novick et al., 1987).

\section{METHODS}

Organisms, growth conditions and plasmids. Escherichia coli strains JM103 and JM107 were obtained from Bethesda Research Laboratories and were grown in $2 \times$ TY medium (Yanisch-Perron et al., 1985).

$S$. aureus strains were grown in CY medium as described by Dyke \& Noble (1984). Strains T48 and J74 were originally isolated from infected patients in Miami, Florida, USA, and London, UK, respectively. pT48 was the only plasmid present in strain $\mathrm{T} 48$, whereas $\mathrm{J} 74$ contained, in addition to the $2.5 \mathrm{~kb}$ erythromycin-resistanceconferring plasmid, pJ74, a $3.2 \mathrm{~kb}$ plasmid, thought to be involved in conferring resistance to cadmium ions (unpublished observations). Strain RN4220, a restriction-minus derivative of the 8325-N strain, which contains neither antibiotic resistance markers nor plasmid (Fairweather et al., 1983), was used as a host for transfer of plasmids by the polyethylene glycol protoplast fusion technique (Götz et al., 1981), to obtain strains with single plasmids in the same background.

Tests for inducible or constitutive nature of MLS resistance. The inducible or constitutive nature of MLS resistance was determined on solid medium using erythromycin $(10 \mu \mathrm{g})$ and tylosin tartrate $(500 \mu \mathrm{g})$ discs, as described by Weisblum et al. (1979).

Plasmid preparation and restriction endonuclease analysis. Plasmid DNA was prepared by a cleared lysate procedure and purified by caesium chloride/ethidium bromide density-gradient centrifugation as described by Novick et al. (1979). Plasmid pJ74 $(2.5 \mathrm{~kb})$ was separated from the $3.2 \mathrm{~kb}$ J74 plasmid by low-melting-point agarose gel electrophoresis and isolated by standard DNA fragment purification procedures (Maniatis et al., 1982). Restriction endonuclease maps were determined for pT48 and pJ74 using single and double enzyme digestions and any ambiguities were resolved using the nucleotide sequence data. Restriction enzymes were purchased from a variety of sources: Amersham, Boehringer Mannheim, New England Biolabs and Bethesda Research Laboratories; they were used according to the manufacturers' instructions.

Nucleotide sequence determination. Restriction enzyme fragments from pT48 and pJ74 were cloned into the M13 filamentous phage vectors mp10, mpl1, mp18 and mp19 (Norrander et al., 1983). DNA sequence was determined by dideoxynucleotide chain termination in the presence of $\left[\alpha^{35}\right.$ S $]$ dATP (Sanger et al., 1977). Labelled fragments were separated on buffer-gradient polyacrylamide/urea gels (Biggin et al., 1983). Klenow fragment and T4 DNA ligase were supplied by Boehringer Mannheim. Deoxynucleotides, dideoxynucleotides and $\left[\alpha^{35}\right.$ S $] \mathrm{dATP}$ were purchased from Amersham. All were used in accordance with the manufacturer's instructions. 


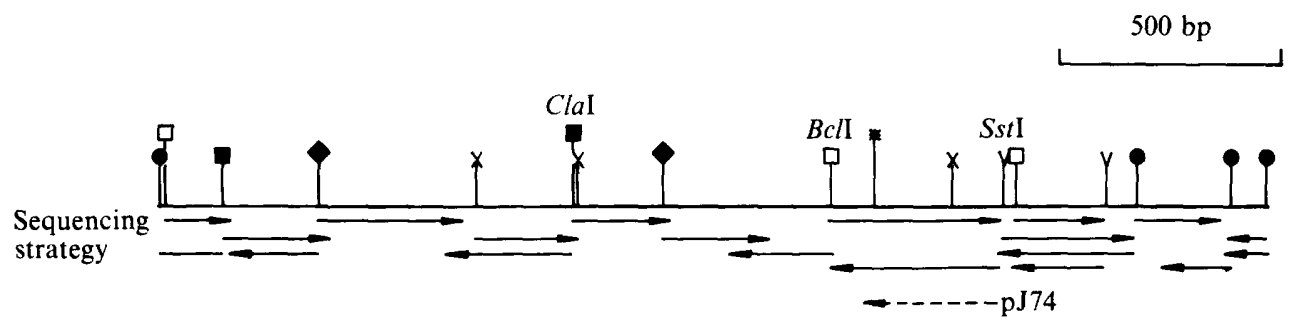

Fig. 1. Partial restriction endonuclease map, and sequencing strategy, for pT48. A dashed arrow shows also the sequencing strategy for a region of pJ74. Restriction enzyme site key: *, HaeIII; V, HgiAI;, HindIII; $\times$, Hinf I; $\diamond, H p a I ; \square, M b o I ; \square, T a q I$.

\section{RESULTS AND DISCUSSION}

\section{Nucleotide sequence of pT48}

A restriction enzyme map of pT48 was obtained using standard techniques and this is shown partially in Fig. 1. This also demonstrates the sequencing strategy used to determine the complete nucleotide sequence of pT48, shown in Fig. 2. In both figures the same HindIII site is used as the reference point for base-pair numbering. Overlapping sequences were obtained for all the sites used for cloning into M13 except for the unique $B c I I$ and $S s t \mathrm{I}$ sites, and a single HindIII site. The sequence was determined on both strands for about $65 \%$ of pT 48 . The plasmid contains 2475 bp.

\section{Nucleotide sequence of part of pJ74}

The size and restriction enzyme map of pJ74 is indistinguishable from that of pT48 except for the loss of a unique HaeIII site and a deletion of about $70 \mathrm{bp}$ between the unique $S s t \mathrm{I}$ and $\mathrm{BclI}$ sites of the latter plasmid. pJ74 confers constitutive MLS resistance whereas pT48 confers inducible resistance. To determine the molecular basis for this difference the small $S s t \mathrm{I} / \mathrm{Bcl} \mathrm{I}$ fragment of pJ 74 was cloned into $\mathrm{M} 13 \mathrm{mp} 19$ and the sequence determined in one direction from the SstI site (see Fig. 1). This sequence is shown in Fig. 3; the 235 nucleotides obtained encompass the region of the deletion and the absent HaeIII site with respect to pT48.

\section{Comparative analysis of plasmid sequence data}

The nucleotide sequence of the $S$. aureus plasmid pT48 is similar to those of $S$. epidermidis plasmid pNE131 (Lampson \& Parisi, 1986b) and B. subtilis plasmid pIM13 (Monod et al., 1986). It also contains regions homologous to the $S$. aureus plasmids pE194, conferring MLS resistance (Horinouchi \& Weisblum, 1982), and pSN2, cryptic (Khan \& Novick, 1982). A comparison of these homologies and the structural features of the homologous plasmids are shown, together with plasmids pJ74, in Fig. 4. The differences between the six plasmids are discussed in the following sections.

(a) Region of homology to pE194. pT48 contains a 1182 bp region of homology to pE194, beginning at nucleotide 911 (Fig. 2), which includes the ermC gene conferring a 23S rRNA methylase and the leader region controlling its expression (Horinouchi \& Weisblum, 1982). This region is basically the same as in plasmid pNE131, the major difference being a 107 bp deletion in the leader region of the latter plasmid. Exactly the same deletion is found in the B. subtilis constitutive MLS resistance plasmid pIM13 (Monod et al., 1986). The regions specifying the methylase and the leader are discussed separately. The only differences between pT48 and pNE131 within the pE194 homologous region which is not involved in MLS resistance are (see Fig. 2): within pT 48 with respect to pNE131 there is an extra $G$ at nucleotide 962 (also present in pIM13), a G at nucleotide 2019 instead of a C, and a GT at 2060-2061 instead of a TG; an A is absent between nucleotides 2061 and 2062; and there is an insertion of the dinucleotide TT as bases 2079 and 2080. The differences are all as in pT48 in the sequence of pE194, except for the latter TT insertion which is absent (Horinouchi \& Weisblum, 1982). 


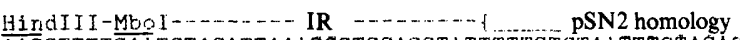

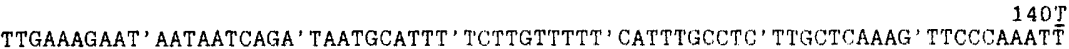
AACTTTCTTA' T'PATT'AGTCT' ATTACGTAAA' AGAACAAAAA' 'GTAAAGGGAG' AACGAGTTTG' AAGGGTT'I'AA ysPheSerTy rTyrAspSer LeuAlaAsng luGlnLysGl uAsnAlaGlu GInGLuPheA snGlyPheGI

agI

210

CGAGTAAGAG' GTATTTT'TGT' TTTTGGTCGT' CGCCTC'TCAT' TAGTAG'TTCA' GGGTTTAACA ' TTAATACTCC GCTCATTCTC' CATAAAAACA' AAAACCAGCA'GCGGAGAG'TA' ATCATCAAGT' CCCAAATTGT'AA'I'I'ATGAGG uLeuLeuLeu TyrLysGInL ysGlraspAs pGLyArgMet LeuLeuGluP roAsriLeuMe theuValGly

Diel

280 AGTTTTTCTT' TTTATAATAT' TTCCTTCTTC'TAAGATTTTA' AGTGTTGT'I'A 'TTACTGTTTG' 'TAGAC'T'TTT TCAAAAAGAA' AAATA'T'TATA' AAGGAAGAAG' ATTCTAAAAT' 'TCACAACAAT' AATGACAAAC' ATC'I'GAACAA ThrLysArgL ysIleI leAs nGlyGluGlu LeuIleLysL euThrThriL eValThrGin LeuSerThrG

Alul AluI

350 CCTGTAGCT' TTGCTATTTC' TCTTGTTGTA'GCTATCATTG 'TAT TGTTACT' 'TAAGTGGACA' TTATCTAGGA GGACATCGAA' AACGATAAAG ' AGAACAACA'T' CGA'TAGTAAC' A'SAACAATGA' AT'TCACCTGT 'AATAGATCCT lyThrAlaLy sAlaIleGlu ArgThrThrA laIleMetTh rAsnAsnber LeuHisValA sraspleuIl

HpaI

420 TATA GTTAAC' GATTTTAAGT' TT'TTTTCCGC' 'CAATCATATC' TAACATACTT' ATTAATTGCA' CTATATATGC ATATCAATTG' CTAAAATTCA' AAAAAAGGCG' GTTAGTATAG' ATTGTA'TGAA'TAATTAACGT' GATATATACG eTyrAsnVal I leLysLeuL ysLysGlyGl yIleMetAsp LeuMetSerI leLeuGInVa IIleTyrAla

490 CTTTACGAAG' TTACCAGACG' TTTGTTTACG' GTATAACTTG' TCTACCTCTA 'TGACTTCTCC' ACTTTCTTCG GAAATGCTTC' AATGGTCTGC' AAACAAATGC' CATATTGAAC' AGATGGAGAT' ACTGAAGAGG' TGAAAGAAGC LysValPheA snglySerTh rGlnLysArg TyrLeuLysA spValgluI1 eValglugly SerGluGluA

DdeI

560

TCTATGAGCC' 'TCTGAGAGCC' TTTATAGACT' GTTCCATATC' TTTCTTTCAT' CTTT'TTCTCA' CTCCTTATTT AGATACTCGG' AGACTCTCGG ' AAATATCTGA ' CAAGGTATAG ' AAAGAAAGTA' GAAAAAGAGT' GAGGAATAAA spIleLeuAr gGlnSerGly LysTyrValT hrGlyTyrAr gGluLysStart-ORF B SD

630

TAAACTATTC' 'TAACTATATC' ATAACTGTTC' TAAAAAAAAA' AGAACATT TG' TTAAAAGAAA' TTAGAACAAA ATTTGATAAG' ATTGATATAG' TATTGACAAG ' ATTTTT'TT'T' 'TCTTGTAAAC' AATTTTCTTT' AATCTTGT'T $-10$ $-35$

700

ATGAGTGAAA' AATTAGAACA' AACAAATTCC' TTATAAACCT' TATCATCTCA 'ACCTATAT'TA ' AGAT'TTTACC TACTCACTTT' TTAATCT'TGT' TTGTTTAAGG' AATAT'TGGA'ATAG'TAGAGT' TGGATA'TAAT' TC'TAAAATGG

Hirff I

770

TAGTTGAATC' TTCTTTTCTA' TATAAAGCGT' CGGAGCATA'T' CAGGGGGTTA' TCTAACGTAA' ATGCTACCCT ATCAACTTAG ' AAGAAAAGAT' ATAT'TCGCA' GCCTCGTAT'A 'GTCCCCCAAT ' AGATTGCATT' TACGATGGGA

Aat I I
TCGGCTCGCT' TTCGCTCGGC' ATTGACGTCA'GATACT'GCAC' CCCCTGAACO' CCEATGC'TCC' AACAGCAAAA

Aat I I
TCGGCTCGCT' TTCGCTCGGC' AT TGACGTCA'GATAC'TGCAC' CCCLTGAACO' CCOATGC'TCC' AACAGCAAAA AGCCGAGCGA' AAGCGAGCCG ' TAACTGCAGT' CTATGACGTG' GGGGACTTGG' 'GGG'TACGAGG' 'TTGTCGTTT'I'

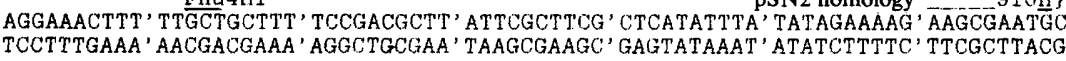

\{haI Rsa I pE194 homology

980 GCAAAAGACA'TA ATCGATC' ACAAAAAATA' GGTACACGAA AACAAGTTA'AGGGATGCAG' TTTATGCATC CGTTTTCTG' ' ATTAGCTAAG' TGT'TTTTAT' CCATGTGCT' 'TTTGT'TCAAT' TCCCTACGTC' AAATACGTAG

AluI AluI $\quad 1050$

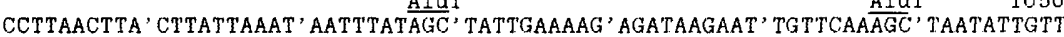
GGAATTGAAT' GAATAATTTA' TTAAATATCG' ATAACTTTTC' TCTATTCTTA' ACAAGTTTCG' ATTATAACAA End LysAsroheL euLysTyrSe rAsnPheLeu SerLeuFheG IrGluPheSe rIleAsnAsn

TAAATCGTCA' ATTCCTGCAT' GTTTTAAGGA ' ATTGTTAAAT' TGATTTTTTG' TAAATATT'TT' CTTGTATTCT ATTTAGCAGT' TAAGGACITA DAAAATTGT' TAAIIATT'TA ACTAAAAAAC' ATTTATAAAA'GAACATAAGA LeuAspaspI leglyAlaHi sLysLeuber AsnAsnPheG lrissilysth rPheIleLys LystyrgluL

HpaI

1190

TTGTTAACCC' ATTTCATAAC ' GAAATAATTA ' TACTTCTGTT' TATCTTTGTG' TGATATTCTT' GATTTTTTTC AACAATTGGG' TAAAGTATTG ' CTTTATTAAT' ATGAAGACAA' ATAGAAACAC' ACTATAAGAA' CTAAAAAAAG ysAsnValTr pLysMetVal PheTyrAsnT yrLysGInLy sAspLyshis SerIleArgs erLysLysAr

'TATTTAATCT' GATAAGTGAG' $\frac{\text { AluI }}{1260}$ ATAAATTAGA' CTATTCACTC' GATAAGTGAA' ATCCAAATCC' TACTTTTAT'A ' AGAGAACCTT' GGTATGAATT gAsnLeuArg IleLeuSerS erAsnValLy sProLysfro HisPheTyrg luArgProVa IMetSerLeu

TATAGAAATA' TCAACTTCTG' CCATTAAAAG' TAATGCCAAT' GAGCGTTTTG'TATTTAATAA' TCTTTTAGCA ATATCTTTAT' AGTTGAAGAC' GGTAATTTTC' ATTACGGTTA 'CTCGCAAAAC' ATAAATTATT' AGAAAATCGT IleSerIleA spValgluAl aMetLeuLeu LeuAlaLeuS erArgLysTh rAsnLeuLeu ArgLysAlaP 
AACCCGTATT' CCACGATTAA'ATAAATCTCA'TCAGCTATAC' TATCAAAAAC' AATTTTGCGT' ATTATATCTG TTGGGCATAA' GGTGCTAAT' 'TATTTAGAGT' AGTCGATATG' ATAGT'I'T'TTG' TTAAAACGCA' TAATATAGAC heGlyTyrgl uValileLeu TyrIleGluA spAlaIlese rAspPheVal IleLysArgI leIleAspTh

SaI

TACTTATGTT' ATAAGGTATA' TTACCAAATA' TTTTATAGGA' TTGGTTTTTA' GGAAATTTAA' ACTGCAATAT ATGAATACAA' TATTCCATAT' AATGGTTTAT' AAAATATCCT' AACCAAAAAT' CCTT'TAAAT'T' TGACGTTATA rSerIleAsn TyrProIleA snGlyPheII eLysTyraer GlnAsnLysP roPheLysPh eGlnLeuIle

$\mathrm{BCl}$ I

1540

ATCCTTGTTT' AAAACTTGGA' AATTATCGTG' ATCAACAAGT' TTATTTTCTG' TAGTTTTGCA' TAATTTATGG TAGGAACAAA' TTTTGAACCT' TTAATAGCAC' TAGTTGTTCA' AATAAAAGAC' ATCAAAACG'T' ATTAAATACC AspLysAsnL euValGInPh eAsnAspHis AspValteuL ysAsngluTh rThrLysCys LeuLysHisA

Ksal

Hae III 1610 DdeI

TCTATTTCAA' TGGCAGTTAC' GAAATTACAC' CTCTGTACTA 'ATTCAAGGG' ' AAAATGGCCT' TTTCCTGAGC AGATAAAGTT' ACCGTCAATG' CTTTAATGTG' GAGACATGAT' TAAGT'TCCCA' TT'TACCGGA AAAGGACTCG spIleGluIl eAlaThrVal PheAsncysA rgGinValLe uGluLeuThr PheHisGlyL ysGlySerGl

CGATTICAAA' GATATATTA'

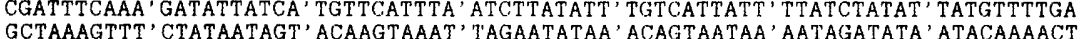
yIleGluPhe IleAsnAspH isGluAsnLe uArgIleAsn ThrMetIleL ysAspIleAs riHisLysGer

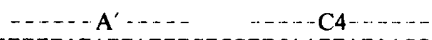
$--C 3--1750$ AGTAATAAAG' TTTTGACTGT' GTTTTATATT' 'TTTCTCGTTC' ATTATAACCC' TCTTTAATTT' GGTTATAATG TCATTATTTC' AAAACTGACA ' CAAAATATAA' AAAGAGCAAG' TAATAT'TGGG 'AGAAATTAAA' CCAATAT TAC ThrIlePheA snGliserHi sLysIleAsn LysGluAsristart ermC SD-22

Hinf I - $22 \ldots$ AATTTTGCTT' ATTAACGATT ' CATTATAACC' ACT TATTTTT' TGTTTGGTTG' ATAATGAACT' GTGCTGATTA TTAAAACGAA' 'TAATTGCTAA' GTAATATTGG' TGAATAAAAA' ACAAACCAAC' TAT'TACTTGA' CACGACTAAT EndLysLy sAsnProGin TyrHisValT hrserIleVa

- - - - A

S.st I 1890

CAAAAATAC' ' AAAAATGCCC' ATATTTTTTC' CTCCTTATAA' AATTAGTATA 'ATTATAGCAC' GAGCTCTGAT GTTTTTATGA 'TTTTTACGGG ' TATAAAAAAG' GAGGAAT'ATT'TTAATCATAT' TAATATCGTG' CTCGAGACTA IPheIleser PheIleGlystart leader SD-1 $-10$

Mbol

1960 AAATATGAAC' ATGATGAGT 'ATCGTTAAAT' TTATACTGCA' ATCTGATGCG' ATTATTGAAT' AAAAGATATG TTTATACTTG' TACTACTCAC' TAGCAATTTA' AATATGACGT' TAGACTACGC' TAATAACTTA' 'TTTTCTATAC

$-2030$ AGAGATTTAT' CTAGTTTCTT' TTTTTACAAGA' AAAAAGAAA' GTTCTTAAAG' GTTTTATAGT' TTTGGTCGTA TCTCTAAATA 'GATCAAAGAA' AAAAATG'TTCT' 'TTTTTCTTT' CAAGAATT'TC' CAAAATATCA' AAACCAGCAT

RS-A pE194 homology 2100 GAGCACACGG' 'TTAACGACT' TAATTACGAAG' TAAATAAG' CTAGTGTGTT' TTAGACTTTA 'ATGTTT'TT'TA CTCGTGTGCC' AAATTGCTGA' ATTAATGCTTC' ATTTATTCA' GATCACACAA' AATCTGAAAT' TACAAAAAAT $\mathrm{Hg}$ IAI

RS-B palA

2170 AAGGCATTAG' TGCACT TAAG ' CGTCAGAGCAT' GGCTTTATG ' CCGAGAAAAC' TATTGGTTGG' AATGGCGTGT TTCCGTAATC' ACGTGAATTC' GCAGTCTCGTA' CCGAAATAC' GGCTCTTTTG' ATAACCAACC' TTACCGCACA

GTGTTAGCCA'

GTGTTAGCCA' CACAATCGGT' TTCGAAACCG ' CTCAACCAACC' CCCAAAGTA' CCCTAATTAG' GGTACTTTCA ' TGGTTGAGT'

pal A

2310

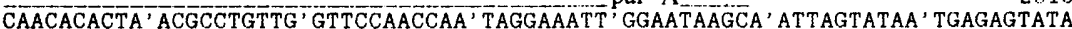
GTTGTGTGAT' TGCGGACAAC' CAAGGTTGGTT' ATCCTTTAA' CCTTATTCGT' TAATCATAT'T' ACTCTCATAT

R.saI ATGTTGGTAT' AACGTTAGTA' TAATGATGCTT' TTTTTCATT' ATATTTTTTA' TGTACTTTAA' ACCTGCACGC TACAACCATA' TTGCAATCAT' ATTACTACGAA' AAAAAGTAA' TATAAAAAAT' ACATGAAATT' TGGACGTGCG

_. TTATGCGAAT' TAGAAAAAGC' 'TTAATCGCATT' TCATAGAT'T' GAC'CTCCCAA' TAACTACGTG' GTGTTATTGG AATACGCTTA' ATCTTTTTCG ' AATTAGCGTAA' AGTATCTAA' CTGGAGGGTT' ATTGATGCAC' CACAATAACC

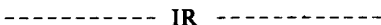

GAGGTCAATC'TATTTCATTT' GCGTT

CTCCAGTTAG' ATAAAGTAAA' CGCAA

Fig. 2. Complete nucleotide sequence of pT48. Numbering starts from the HindIII site shown as the zero co-ordinate in Fig. 1. The amino acid sequence of the putative polypeptides described by open reading frame (ORF) B, erm $C$ and the erm $C$ leader peptide are shown. Structures labelled A, A', C1, C2, $\mathrm{C} 3$ and $\mathrm{C} 4$ represent six complementary base-pairing sequences. SD indicates a Shine-Dalgarno sequence. The ends of homology of pSN2 and pE194 are marked, as are the two recombination sequences: RS-A and RS-B (see text). Two large palindromic structures are shown: palA (see Fig. 6) and IR (inverted repeat) (see Fig. 7). 


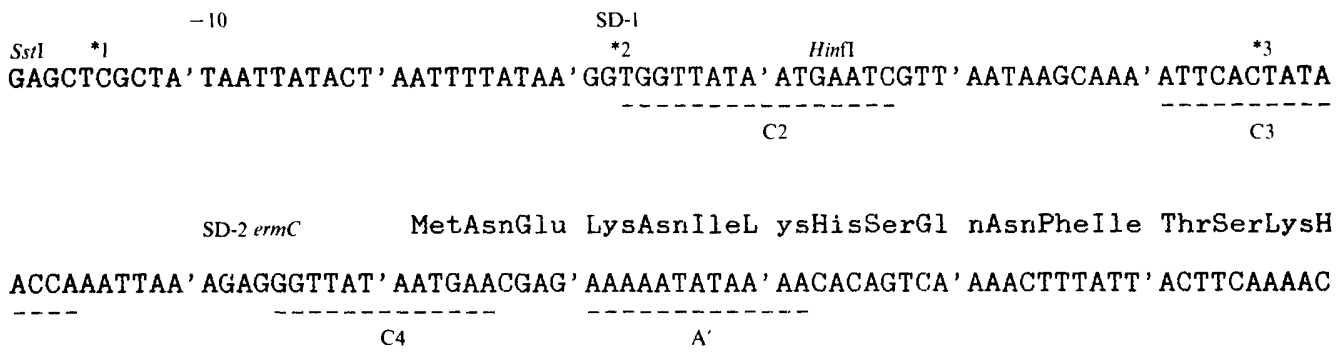

isAsnIleAs pLysIleMet ThrAsnIleA rgLeuAsngl uHisAspAsn IlePheGluI leGlySerGl ATAATATAGA' TAAAATAATG' ACAAATATAA' GATTAAATGA' ACATGATAAT' ATCTTTGAAA' TCGGCTCAGG

\author{
yLysGlyHis PheThrLeug luLeu \\ ${ }^{*} 4$ \\ AAAAGGGCAT' TTTACCCTTG' AATTA
}

Fig. 3. Nucleotide sequence of the ermC control region from pJ74. The sequence of $235 \mathrm{bp}$ from the unique $S s t \mathrm{I}$ site of $\mathrm{pJ} 74$ shows the control region for ermC and the $\mathrm{N}$-terminal portion of the methylase. Features are as in Fig. 2 excepting: ${ }^{*} 1$, loss of GT (nucleotides 1880 and 1879) from comparable region of pT48; ${ }^{*}$, ends of $71 \mathrm{bp}$ deletion with respect to pT48 sequence (nucleotides 1853 and 1781); ${ }^{*}$, nucleotide $C$ is a $T$ at position 1749 in pT48; ${ }^{*} 4$, nucleotide $G$ is a $C$ at position 1579 in pT48.

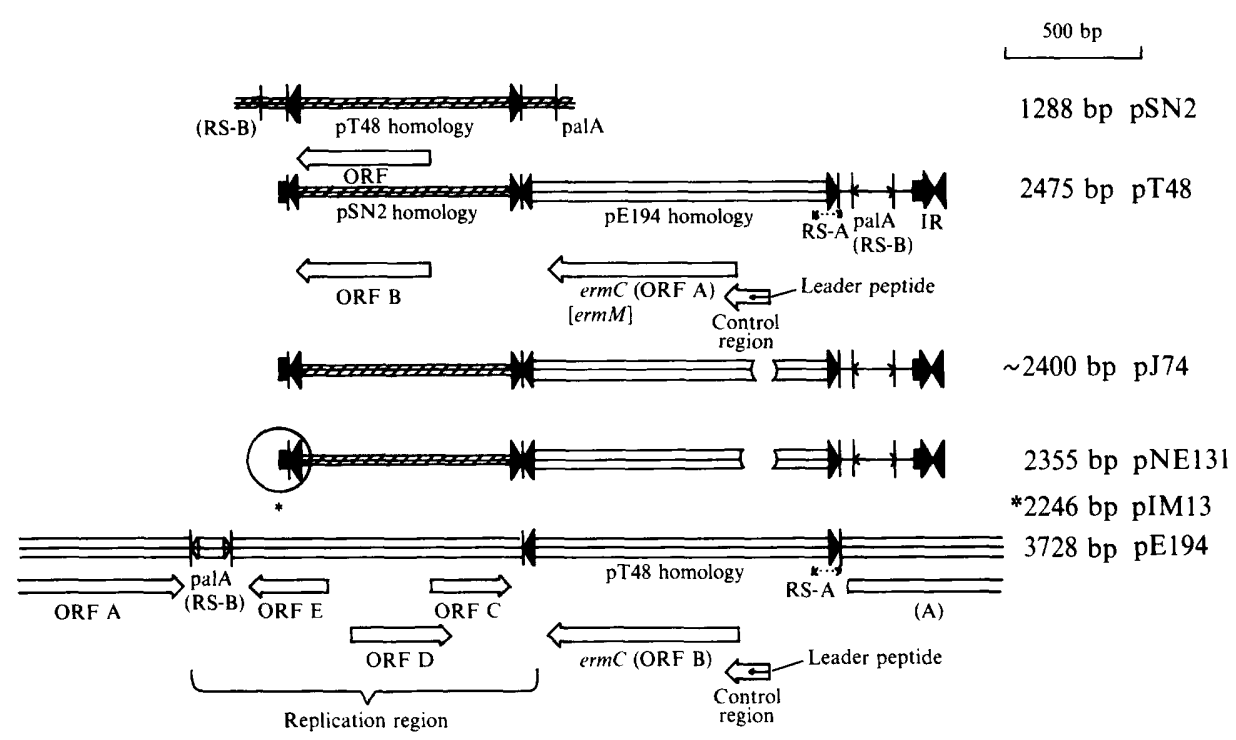

Fig. 4. Functional map of pT48 and comparison to other homologous plasmids. The plasmids are shown linearized to maximize the overlap of homologous regions. ORFs are designated by large open boxes, as is the control region required for inducible expression of erm C. A small arrow denotes the position of the leader peptide within ermC. Gaps represent deletions with respect to the sequence of plasmid pT48 within the ermC leader region. A further deletion within pIM13 with respect to pNE131 is encircled and marked with an asterisk. RS-A (dotted line), and RS-B (part of palA : open arrow heads) represent two distinct recombination sequences. The position of a large inverted repeat (IR) is indicated in thick black. Filled-in arrow heads show the ends of homologous regions. pSN2 homologous regions; E $\mathrm{pE} 194$ homologous regions. 
Table 1. Codon differences within ermC methylases

The comparison of nucleotide sequences for the erm $C$ methylase codons uses capital letters to represent conserved bases and lower case letters where differences occur. Only codons which show a base sequence difference between the erm $C$ regions of the four plasmids (pT48, pNE131, pIM13 and pE194) are shown. Novel amino acids resulting from nucleotide base changes are italicized.

Plasmid

Codon no.

\begin{tabular}{|c|c|c|c|c|c|c|c|c|c|c|}
\hline & 42 & 50 & 99 & 108 & 121 & 134 & 142 & 145 & 177 & 189 \\
\hline pT48 & $\begin{array}{l}\text { GGc } \\
\text { Gly }\end{array}$ & $\begin{array}{l}\text { cAG } \\
\text { Gln }\end{array}$ & $\begin{array}{l}\text { TtT } \\
\text { Phe }\end{array}$ & $\begin{array}{l}\text { ACa } \\
\text { Thr }\end{array}$ & $\begin{array}{l}\text { gAT } \\
\text { Asp }\end{array}$ & $\begin{array}{l}\mathrm{AGa} \\
\mathrm{Arg}\end{array}$ & $\begin{array}{l}\text { TTg } \\
\text { Leu }\end{array}$ & $\begin{array}{l}\text { cTT } \\
\text { Leu }\end{array}$ & $\begin{array}{l}\text { AaT } \\
\text { Asn }\end{array}$ & $\begin{array}{l}\text { CAg } \\
\text { Gln }\end{array}$ \\
\hline pNE131 & $\begin{array}{l}\text { GGg } \\
\text { Gly }\end{array}$ & $\begin{array}{l}\text { cAG } \\
\text { Gln }\end{array}$ & $\begin{array}{l}\text { TtT } \\
\text { Phe }\end{array}$ & $\begin{array}{l}\mathrm{ACg} \\
\text { Thr }\end{array}$ & $\begin{array}{l}\text { gAT } \\
\text { Asp }\end{array}$ & $\begin{array}{l}\mathrm{AGg} \\
\mathrm{Arg}\end{array}$ & $\begin{array}{l}\text { TTc } \\
\text { Phe }\end{array}$ & $\begin{array}{l}\text { tTT } \\
\text { Phe }\end{array}$ & $\begin{array}{l}\text { AaT } \\
\text { Asn }\end{array}$ & $\begin{array}{l}\mathrm{CAg} \\
\text { Gln }\end{array}$ \\
\hline pIM13 & $\begin{array}{l}\text { GGg } \\
\text { Gly }\end{array}$ & $\begin{array}{l}\text { cAG } \\
\text { Gln }\end{array}$ & $\begin{array}{l}\text { TtT } \\
\text { Phe }\end{array}$ & $\begin{array}{l}\mathrm{ACg} \\
\text { Thr }\end{array}$ & $\begin{array}{l}\text { gAT } \\
\text { Asp }\end{array}$ & $\begin{array}{l}\mathrm{AGa} \\
\mathrm{Arg}\end{array}$ & $\begin{array}{l}\text { TTg } \\
\text { Leu }\end{array}$ & $\begin{array}{l}\text { tTT } \\
\text { Phe }\end{array}$ & $\begin{array}{l}\text { AaT } \\
\text { Asn }\end{array}$ & $\begin{array}{l}\mathrm{CAg} \\
\text { GIn }\end{array}$ \\
\hline pE194 & $\begin{array}{l}\text { GGc } \\
\text { Gly }\end{array}$ & $\begin{array}{l}\mathrm{aAg} \\
\text { Lys }\end{array}$ & $\begin{array}{l}\text { TaT } \\
\text { Tyr }\end{array}$ & $\begin{array}{l}\text { ACg } \\
\text { Thr }\end{array}$ & $\begin{array}{l}\mathrm{aAT} \\
A s n\end{array}$ & $\begin{array}{l}\text { AGa } \\
\text { Arg }\end{array}$ & $\begin{array}{l}\text { TTg } \\
\text { Leu }\end{array}$ & $\begin{array}{l}\text { cTT } \\
\text { Leu }\end{array}$ & $\begin{array}{l}\mathrm{AgT} \\
\text { Ser }\end{array}$ & $\begin{array}{l}\text { CAa } \\
\text { Gln }\end{array}$ \\
\hline
\end{tabular}

(i) Region specifying the methylase (ermC). A 244 amino acid open reading frame (ORF) of pT48 bearing $>99 \%$ homology to ermC of pE194 is assumed to encode the methylase enzyme (Horinouchi \& Weisblum, 1982). The codon usage of these two ermC genes is compared with that of the ermM methylase (from pNE131) and the similar gene from pIM13 in Table 1. All four methylases are 244 amino acids long. The methylases conferred by pT48 and pNE131 share identical amino acids apart from positions 142 and 145, where in both cases Leu in pT48 has changed to Phe in pNE131. The pIM13 methylase is identical to that of pNE131 apart from codons 134 and 142, which are as in pT 48 for the $B$. subtilis plasmid. The methylase specified by pE194 shows four further changes from that of pT48 and, therefore, six in all from that of pNE131. Most of the changes significantly alter the type of amino acid found in that position and therefore must represent amino acids that have no significant role in methylase function. The differences represent point mutations distributed throughout the gene. These changes, taken together with those in the rest of the pE194 homologous region, imply that, within the process of genetic drift, pT48 is more closely related to pE194 than is pNE131 or pIM13, for this region. It is interesting that for $\mathrm{pJ} 74$, where only the first 48 codons of the methylase are known (Fig. 3), codon 42 is as in pNE131. This represents a change of $\mathrm{C}$ to $\mathrm{G}$ from pT48 to pNE131 and pJ74. In all cases it results in the loss of the unique HaeIII site found in pT48.

(ii) Leader region controlling methylase expression. For pE194 a translational attenuation model has been proposed to explain the inducibility of its ermC gene by sub-inhibitory concentrations of erythromycin (Dubnau, 1984; Weisblum, 1984). The molecular basis of this model relies upon the translation of a 19 amino acid leader peptide (Dubnau, 1985) and the presence of six complementary base-pairing regions $5^{\prime}$ to the methylase-coding region (Horinouchi \& Weisblum, 1982). This is known as the ermC leader region. An identical region, apart from an extra A at nucleotide 1748 (Fig. 2), can be found in plasmid pT48, which also shows inducible ermC expression. The other plasmids for which this region has been sequenced, pJ74 (Fig. 3), pNE131 (Lampson \& Parisi, 1986a) and pIM13 (Monod et al., 1986) all confer constitutive MLS resistance. The leader regions of these plasmids show large deletions with respect to pT48 (see Fig. 4): 71 bp for pJ74 (1783-1852 bp) and $107 \mathrm{bp}$ for pNE131 and pIM13 (1737-1842 bp). These data are shown in Fig. 5 together with a schematic representation of the control of ermC expression in pT48. The Pribnow box $(-10)$, transcription start site, leader peptide and ShineDalgarno sequences ( 1 and 2 ) are so designated from their identity to such features in pE194 (Horinouchi \& Weisblum, 1982). The region shown in Fig. 5 is identical to that in plasmids pJ74, pNE131 and pIM13 apart from the differences shown.

Fig. 5 shows the simplest interpretation of the translational attenuation model (Dubnau, 1984; Weisblum, 1984) as applied to pT48. The methylase encoded by ermC mediates $N^{6}, N^{6}-$ dimethylation of adenine in $23 \mathrm{~S}$ rRNA and this results in reduced affinity of the $50 \mathrm{~S}$ ribosomal 


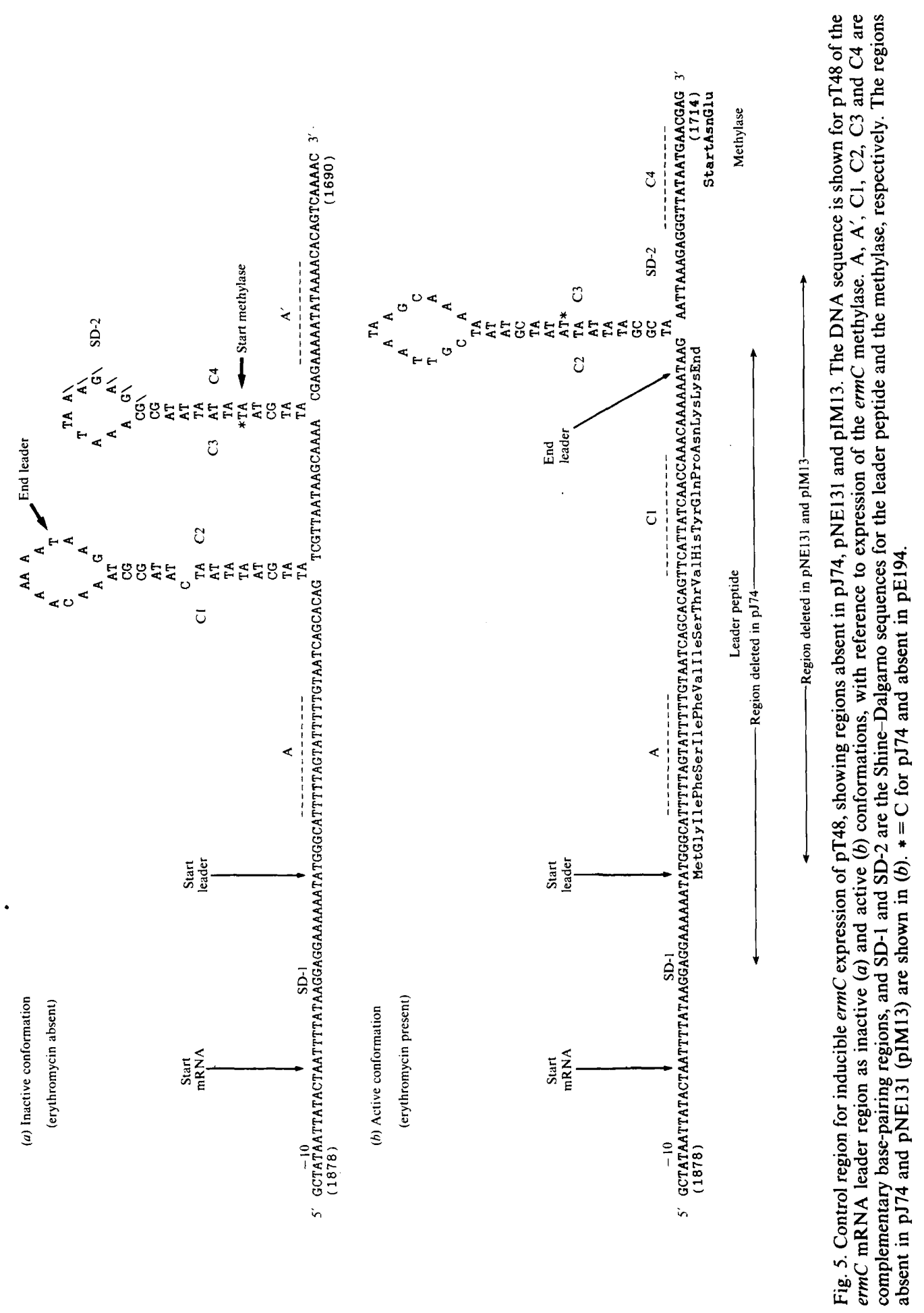


sub-unit for MLS antibiotics. MLS resistance is conferred since the antibiotics can no longer inhibit protein synthesis by stalling the ribosomal peptidyl transferase enzyme. Induction relies upon the use of this inhibition. Two possible conformations of the ermCleader region are shown as DNA sequence in Fig. 5, but the mechanism works at the mRNA level. In $(a)$, the uninduced state, only SD-1 is accessible to ribosomes, so only the leader peptide is translated. SD-2 is sequestered within the energetically favourable complementary base-paired structures shown and methylase is not expressed. In the presence of erythromycin, ribosomes can stall whilst translating the leader peptide and can stabilize the active conformation shown in Fig. $5(b)$. In this instance, the region $\mathrm{C} 1$ is prevented from binding its complementary repeat $\mathrm{C} 2$, and now the more energetically favourable situation is for $\mathrm{C} 2$ to bind $\mathrm{C} 3$, thus freeing region $\mathrm{C} 4$. This unmasks SD-2, allowing the methylase enzyme to be translated (Dubnau, 1984; Weisblum, 1984). In the case of $\mathrm{pJ} 74$, both the leader peptide and region $\mathrm{Cl}$ are deleted, leaving its ermC mRNA leader effectively stuck with $\mathrm{C} 2$ and $\mathrm{C} 3$ paired as in conformation $(b)$. This can explain why MLS resistance is constitutively expressed in pJ74. A similar phenotype is shown by pNE131, but as can be seen in Fig. 5(b), both the deletion and the explanation for constitutivity are slightly different. In pNE131, the leader peptide, $\mathrm{C} 1, \mathrm{C} 2$ and $\mathrm{C} 3$ are deleted, so that no complementary base-pairing regions can form. However, the leader region is again fixed in a conformation in which SD-2 is permanently exposed, and so methylase expression is constitutive. Both of these naturally occurring deletions are similar to those obtained in vitro with $\mathrm{pE} 194$, either by growth of bacterial strains on tylosin plates (Horinouchi \& Weisblum, 1981), or generated by Bal31 exonuclease digestion (Hahn et al., 1982), to produce constitutive mutants. Indeed, the $3^{\prime}$ end-point of the deletion in pJ74 (at nucleotide 1783 in pT48) exactly matches the $3^{\prime}$ end of one such mutant selected on tylosin (Horinouchi \& Weisblum, 1981). The role of antibiotic usage in the clinical environment in producing such constitutive mutants has been discussed (Lampson \& Parisi, 1986a).

It is interesting that the extra A-T base-pair found at nucleotide 1748 in pT48, but absent in the equivalent region of pE194, results in greater stability of both the C2:C3 and C3:C4 complementary base-paired structures (Horinouchi \& Weisblum, 1982). In both cases this is by virtue of an extra $\mathrm{A}$ : T base pairing. The equivalent region in pJ74 contains a $\mathrm{G}-\mathrm{C}$ base-pair which lowers the energy of the $\mathrm{C} 2: \mathrm{C} 3$ structure by creating an interior loop, instead of a bulge loop (as in pE194), in the base-paired secondary structure (Tinoco et al., 1973).

(b) Region of homology to pSN2. pT48 has $87 \%$ homology to an 878 bp region of the cryptic $S$. aureus plasmid pSN2 (Khan \& Novick, 1982), from nucleotides 33 to 910 (Fig. 4). This includes a 158 amino acid ORF designated ORF B by its similarity to the equivalent ORF in pNE131 (Lampson \& Parisi 1986b). These two ORF Bs have identical DNA sequences apart from the deletion of two bases (AG) between nucleotides 93-94 in pT48, which results in a C-terminal frameshift. As a consequence, ORF B in pT48 is four amino acids shorter than in pNE131, and its final eight amino acids are different. The C-terminus of the pT48 ORF B is the same as that of the pSN2 ORF apart from two changes of Asp to Glu at amino acids 152 and 158 (Khan \& Novick, 1982). The equivalent ORF in pIM13, ORF 3, is truncated with respect to that of PT48 due to a deletion from nucleotide 2464-109 in the former plasmid compared to the pT48 sequence. This results in the removal of the final 14 amino acids of the pT48 ORF and their replacement by only two: Ile and Asp (Monod et al., 1986). The ' -10 ' and '-35' sequences, and the Shine-Dalgarno 'ribosome-binding site' are assumed to be as in pNE131 (Lampson \& Parisi, $1986 b$ ).

pSN2 has been shown to direct the synthesis of $20 \mathrm{kDa}$ and $12 \mathrm{kDa}$ polypeptides in coupled transcription-translation systems, based on cell extracts, in vitro. This is presumably due to its ORF (Khan \& Novick, 1982). Although the function of the encoded polypeptide/s is unknown, a role has been suggested in plasmid replication and maintenance for the pIM13 ORF 3 which appears to encode only a $16 \mathrm{kDa}$ polypeptide (Monod et al., 1986).

The only other differences between pT48 and pNE131 within this region are: a T insertion at nucleotide 52, the sequence TCGCT (bases 873-877) is reduced to CTG in pNE131 (the pT48 sequence is also seen in pSN2 and pIM13), and nucleotide 904 is a C instead of a $\mathrm{T}$, again as in pSN2 (See Fig. 2). 


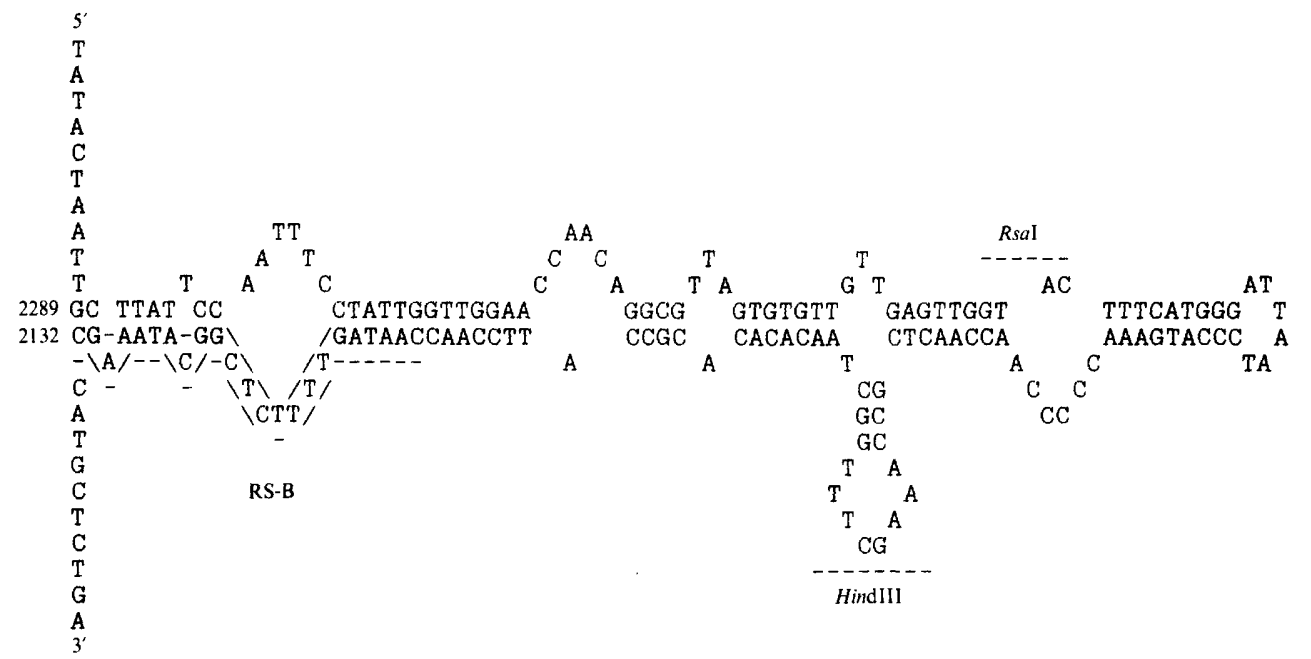

Fig. 6. The palA region of pT48. RS-B represents the core sequence of a specific recombination sequence (Gruss \& Novick, 1987; Novick et al., 1987).

It is interesting that one end of the pSN2 homology in pT48 (nucleotide 33: Fig. 2) stops just before the beginning of a short inverted repeat in pSN2 (Khan \& Novick, 1982). This is thought to be the transcription stop signal for the mRNA encoding the pSN2 ORF polypeptide. The equivalent mRNA in pT48 must, therefore, use a different transcriptional stop signal.

(c) Remainder of pT48. The remaining 413 bp of pT48 bears no extensive DNA sequence homology to either pE194 or pSN2, and contains two large palindromic structures: (i) palA (Fig. 6) and (ii) inverted repeat (IR) (Fig. 7). There are a number of nucleotide sequence differences between pT48 and pNE131 within this region, which are not involved in the formation of the palindromic structures. For $\mathrm{pT} 48$, there is an $\mathrm{A}$ instead of a $\mathrm{T}$ at nucleotide 2100 , a $\mathrm{C}$ at base pair 2115 not a T (the latter difference generates a $\mathrm{HgiAI}$ site in pT48, not seen in pNE131), and there is an 11 bp insertion at nucleotides 2294-2304, with respect to pNE131, 9 bp of which are duplicated in the immediate $3^{\prime}$ sequence (see Fig. 2). This latter insertion is also seen in pIM13 (Monod et al., 1986).

(i) palA. This is an imperfect palindrome of about $156 \mathrm{bp}$ from nucleotides 2132 to 2289 in pT48 (Fig. 6). It is designated palA by analogy to other such structures seen in many other small $S$. aureus plasmids (Gruss et al., 1987; Novick et al., 1987). The lowest free energy value, $\Delta \mathrm{G}$, for the pT48 palA structure (Fig. 6), is estimated at $-45.8 \mathrm{kcal} \mathrm{mol}^{-1}\left(191.6 \mathrm{~kJ} \mathrm{~mol}^{-1}\right)$ (Tinoco et al., 1973). Such structures are thought to be origins of replication for negative-strand DNA synthesis. Studies on one $S$. aureus plasmid, pT181, have shown that upon deletion of palA, single-stranded DNA, equivalent to the displaced plus strand in replication, accumulates more than in the wild-type plasmid (Gruss et al., 1987; Novick et al., 1987; Te Riele et al., 1986a,b). The palA regions of other small $S$. aureus plasmids are thought to have similar roles. Such structures were originally defined as recombination hot-spots (RS-B) for plasmid co-integrate formation (Novick et al., 1984). Consistent with this is the presence of an RS-B core sequence at one end of the pT48 structure (Fig. 6) as seen in other palAs. This means that only 38 bp separate the ends of two specific recombination sequences in pT48: RS-B and RS-A, seen at one end of the pE194 homologous region (2026-2092 nucleotides). Despite the fact that pT48 contains two common recombination sequences involved in the co-integrate formation of several small $S$. aureus plasmids, it is still not clear how (or whether) pT48 was formed by recombination between pSN2 and pE194. The origin of the $413 \mathrm{bp}$ region unrelated to pSN2 is also still unknown. The pT48 palA is very different to those of both pSN2 and pE194 and shows considerable homology to that of the $S$. aureus plasmid pT181 (Gruss et al., 1987; Novick et al., 1987). There is just one difference between the palA sequence of pT48 and pNE131, a deletion 


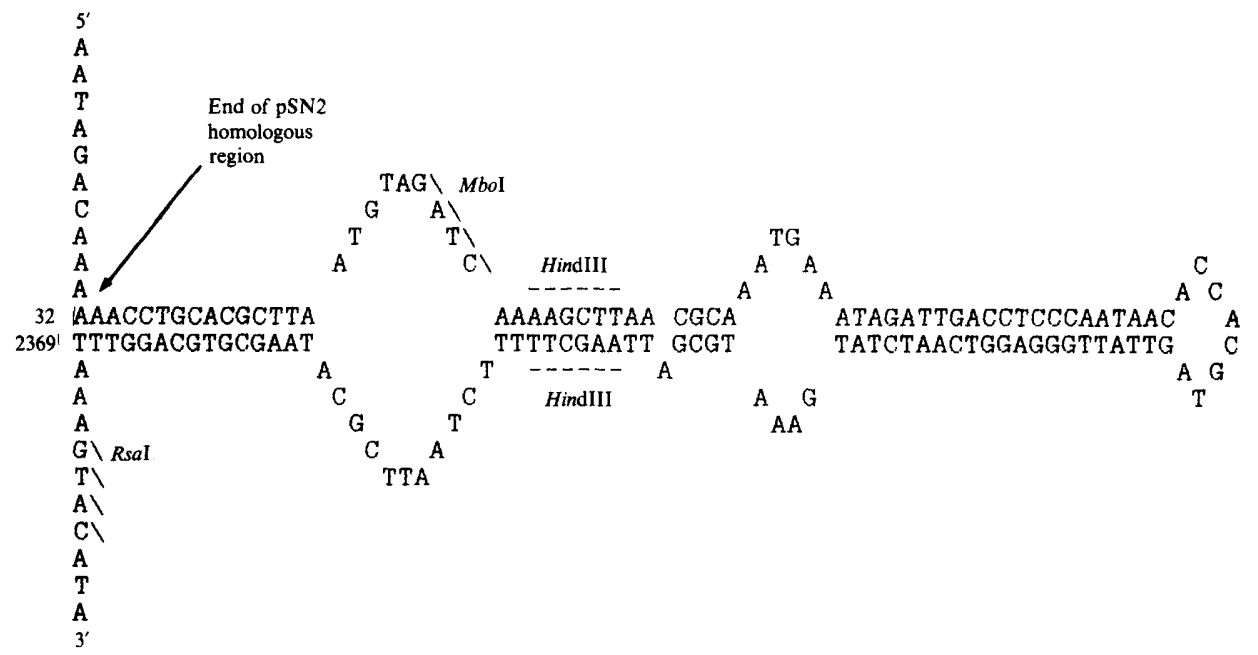

Fig. 7. Large inverted repeat (140 bp). The imperfect palindrome shown covers nucleotides $2369-32$ in the sequence of pT48.

within the former sequence of an A between nucleotides 2136-2137 (see Fig. 2). The extra $\mathrm{A}$ is also absent in pIM13 (Monod et al., 1986).

(ii) Inverted repeat (IR). An imperfect inverted repeat of approximately $70 \mathrm{bp}$ is shown as its lowest free energy structure, a palindrome of $\Delta \mathrm{G}$ about $-45.5 \mathrm{kcal} \mathrm{mol}^{-1}\left(190.4 \mathrm{~kJ} \mathrm{~mol}^{-1}\right)$ in Fig. 7 (Tinoco et al., 1973). The palindrome encompasses nucleotides $2369-32$ in pT48, and similar structures have not been seen in other $S$. aureus plasmids. The deletion in pIM13 from nucleotide 2464-109 in the pT48 sequence also results in the loss of most of this palindrome, although inverted repeats of about $21 \mathrm{bp}$ are still present (Monod et al., 1986). It is as yet unclear if this structure has a defined function but it may be postulated to act as a transcriptional terminator for the mRNA encoding the ORF B polypeptide, although it is a little large for such a structure. It may also have a functional role in the resolution of pT48 multimeric replication complexes to supercoiled plasmid monomers (unpublished data, this laboratory). Plasmid pIM13 is naturally highly multimeric (Monod et al., 1986). It is interesting that one edge of the palindrome starts exactly as one end of the $\mathrm{pSN} 2$ homologous region finishes, i.e. at nucleotide 32 (see Fig. 7). There are three changes within this region in pT48 compared to pNE131: the C present at nucleotide 2386 is a $\mathrm{T}$ in pNE131, a C is inserted at base pair 2423 in the former plasmid and there is the deletion of an A between nucleotides 2435-2436 in pT48. The latter two differences are as in pT48 for pIM13 and lead to increased stability of the structure shown in Fig. 7 for $\mathrm{pT} 48$.

\section{Evolution of staphylococcal MLS resistance plasmids}

It seems likely that inducible MLS resistance plasmids such as pT48 represent an evolutionary intermediate between plasmids like the cryptic pSN2 and the inducible MLS resistance plasmid pE194; and constitutive MLS resistance plasmids such as pJ74 and pNE131. However, the direction of this evolutionary relationship between pT48, and pSN2 and pE194 is not so clear.

It is also probable that mutations changing inducible MLS resistance to the constitutive phenotype can occur independently in different clinical environments. Transfer of such a mutated plasmid from $S$. aureus to $S$. epidermidis, rather than in the opposite direction, is implicated on this occasion (Lampson \& Parisi, 1986 ; Cohen et al., 1982). Transfer to B. subtilis followed by further mutations also seems likely in the case of pIM13 (Monod et al., 1986).

Note added in proof. Whilst this paper was in press, a report of the nucleotide sequence of another $S$. aureus plasmid, pE5, conferring inducible MLS resistance was published (Projan et al., 1987). The sequence of pE5 is nearly identical to that of pT48. 
The authors would like to thank Mrs A. Day and Mr D. Ramsay for their help with the manuscript and figures. I.R.C. is supported by a studentship from the SERC.

\section{REFERENCES}

Bastos, M., Bonaldo, M. \& Penido, E. (1980). Constitutive erythromycin resistance plasmid in Staphylococcus aureus. Journal of General Microbiology 133, 513-516.

Biggin, M., Gibson, T. \& Hong, G. (1983). Buffer gradient gels and ${ }^{35} \mathrm{~S}$ label as an aid to rapid DNA sequence determination. Proceedings of the National Academy of Science of the United States of America 80 , 3963-3965.

Clewell, D. (1981). Plasmids, drug resistance and gene transfer in the genus Streptococcus. Microbiological Reviews 45, 409-436.

Cohen, M., Wong, E. \& Falkow, S. (1982). Common R-plasmids in Staphylococcus aureus and Staphylococcus epidermidis during a nosocomial $S$. aureus outbreak. Antimicrobial Agents and Chemotherapy 21, 210-215.

Docherty, A., Grandi, G., Grandi, R., Gryczan, T., Shivakumar, A. \& DubnaU, D. (1981). Naturally occurring macrolide-lincosamide-streptogramin B resistance in Bacillus licheniformis. Journal of Bacteriology 145, 129-137.

Dubnau, D. (1984). Translational attenuation: the regulation of bacterial resistance to the macrolidelincosamide-streptogramin B antibiotics. CRC Critical Reviews in Biochemistry 16, 103-132.

DuBNAU, D. (1985). Induction of ermC requires translation of the leader peptide. EMBO Journal 4, 533-537.

Dyke, K. \& Noble, W. (1984). Plasmids of phage group II - Staphylococcus aureus. Journal of Medical Microbiology 17, 325-334.

FaIRWEather, N., KenNedy, S., Foster, T., KeHoe, M. \& Dougan, G. (1983). Expression of a cloned Staphylococcus aureus $\alpha$-hemolysin determinant in Bacillus subtilis and $S$. aureus. Infection and Immunity 41, 1112-1117.

Fujisawa, Y. \& Weisblum, B. (1981). A family of rdeterminants in Streptomyces spp. that specifies inducible resistance to macrolides, lincosamides and streptogramin type B antibiotics. Journal of Bacteriology 148, 621-631.

GötZ, F., AHrNí, S. \& Lindberg, M. (1981). Plasmid transfer and genetic recombination by protoplast fusion in staphylococci. Journal of Bacteriology 145, 74-81.

Gruss, A., Ross, H. \& Novick, R. (1987). Functional analysis of a palindromic sequence required for normal replication of several staphylococcal plasmids. Proceedings of the National Academy of Sciences of the United States of America 84, 21652169.

Gryczan, T., Grandi, G., Hahn, J., Grandi, R. \& DUBNAU, D. (1980). Conformational alteration of mRNA structure and the post-transcriptional regulation of erythromycin induced drug resistance. Nucleic Acids Research 8, 6081-6097.

Gryczan, T., Israeli-Reches, M., Del-Bue, M. \& DUBNAU, D. (1984). DNA sequence and regulation of erm D, a macrolide-lincosamide-streptogramin B resistance element from Bacillus licheniformis. Molecular and General Genetics 194, 349-356.
Hahn, J., Grandi, G., Gryczan, T. \& Dubnau, D. (1982). Translational attenuation of ermC: a deletion analysis. Molecular and General Genetics 186, 204216.

Horinouchi, S. \& Weisblum, B. (1980). Post-transcriptional modification of mRNA conformation: mechanism that regulates erythromycin induced resistance. Proceedings of the National Academy of Sciences of the United States of America 77, 70797083.

HoRinouchi, S. \& Weisblum, B. (1981). The control region for erythromycin resistance: free energy changes related to induction and mutation to constitutive expression. Molecular and General Genetics 182, 341-348.

HoRINOUCHI, S. \& Weisblum, B. (1982). Nucleotide sequence and functional map of pE194, a plasmid that specifies inducible resistance to macrolide, lincosamide and streptogramin-type B antibiotics. Journal of Bacteriology 150, 804-814.

Horinouchi, S., Byeow, W. \& Weisblum, B. (1983). A complex attenuator regulates inducible resistance to macrolides, lincosamides and streptogramin type B antibiotics in Streptococcus sanguis. Journal of Bacteriology 154, 1252-1262.

IORDANESCU, S. \& SuRdeANU, M. (1980). New incompatibility groups for Staphylococcus aureus plasmids. Plasmid 4, 256-260.

Keller, G., Schleifer, K. \& Götz, F. (1983). Construction and characterization of plasmid vectors for cloning in Staphylococcus aureus and Staphylococcus carnosus. Plasmid 10, 270-280.

KhaN, S. \& Novick, R. (1980). Terminal nucleotide sequences of $\mathrm{Tn} 551$, a transposon specifying erythromycin resistance in Staphylococcus aureus: homology with Tn3. Plasmid 4, 148-154.

KHAN, S. \& Novick, R. (1982). Structural analysis of plasmid pSN2 in Staphylococcus aureus: no involvement in enterotoxin B production. Journal of Bacteriology 149, 642-649.

KOLTER, R. \& YANOFSKY, C. (1982). Attenuation in amino acid biosynthetic operons. Annual Review of Genetics 16, 113-134.

LAI, C. \& WeISBLUM, B. (1971). Altered methylation of ribosomal RNA in an erythromycin resistant strain of Staphylococcus aureus. Proceedings of the National Academy of Sciences of the United States of America 68, 856-860.

lai, C., Dahlberg, J. \& Weisblum, B. (1973). Structure of an inducibly methylatable nucleotide sequence in $23 \mathrm{~S}$ ribosomal ribonucleic acid from erythromycin resistant Staphylococcus aureus. Biochemistry 12, 457-460.

LAMPSON, B. \& PARISI, J. (1986a). Naturally occurring Staphylococcus epidermidis plasmid expressing constitutive macrolide-lincosamide-streptogramin B resistance contains a deleted attenuator. Journal of Bacteriology 166, 479-483.

LAMPSON, B. \& PARISI, J. (1986b). Nucleotide sequence of the constitutive macrolide-lincosamide-streptogramin B resistance plasmid, pNE131, from Staphylococcus epidermidis and homologies with Staphylo- 
coccus aureus plasmids pE194 and pSN2. Journal of Bacteriology 167, 888-892.

MAHLER, M. \& HALVorson, H. (1980). Two erythromycin-resistance plasmids of diverse origin and their effect on sporulation in Bacillus subtilis. Journal of General Microbiology 120, 259-263.

Maniatis, T., Fritsch, E. \& Sambrook, J. (1982). Molecular Cloning: a Laboratory Manual. Cold Spring Harbor, NY: Cold Spring Harbor Laboratory.

Monod, M., Denoya, C. \& Dubnau, D. (1986). Sequence and properties of pIM13, a macrolidelincosamide-streptogramin B resistance plasmid from Bacillus subtilis. Journal of Bacteriology 167, 138-147.

MURPHY, E. (1985). Nucleotide sequence of ermA, a macrolide-lincosamide-streptogramin B determinant in Staphylococcus aureus. Journal of Bacteriology 162, 633-640.

Murphy, E., Hunyler, L. \& Bastos, M. (1985). Transposon Tn554: complete nucleotide sequence and isolation of transposition-defective and antibiotic-sensitive mutants. EMBO Journal 4, 3357-3365.

Norrander, J., Kempe, T. \& Messing, J. (1983). Construction of improved M13 vectors using oligodeoxy-nucleotide-directed mutagenesis. Gene 26, 101-106.

Novick, R., Murphy, E., Gryczan, T., Baron, E. \& Edelman, 1. (1979). Penicillinase plasmids of Staphylococcus aureus: restriction-deletion maps. Plasmid 2, 109-129.

Novick, R., Projan, S., Rosenblum, W. \& Edelman, I. (1984). Staphylococcal plasmid co-integrates are formed by host and phage-mediated general rec systems that act on short regions of homology. Molecular and General Genetics 195, 374-377.

Novick, R., Gruss, A., Highlander, S., GenNaro, M., Projan, S. \& Ross, H. (1987). Host-plasmid interactions affecting plasmid replication and maintenance in Gram-positive bacteria. In Antibiotic Resistance Genes: Ecology, Transfer, and Expression (Banbury Report 24), pp. 225-242. Edited by S. Levy \& R. P. Novick. Cold Spring Harbor, NY: Cold Spring Harbor Laboratory.
Parisi, J., Robbins, J., Lampson, B. \& Hecht, D. (1981). Characterization of a macrolide, lincosamide and streptogramin resistance plasmid in Staphylococcus epidermidis. Journal of Bacteriology 148, 559564.

Projan, S., Monod, M., Narayanan, C. \& Dubnau, D. (1987). Replication properties of pIM13, a naturally occurring plasmid found in Bacillus subtilis, and of its close relative $\mathrm{pE5}$, a plasmid native to Staphylococcus aureus. Journal of Bacteriology 169, 5131-5139.

SANGer, F., Nicklen, S. \& Coulson, A. (1977). DNA sequencing with chain-terminating inhibitors. Proceedings of the National Academy of Sciences of the United States of America 74, 5463-5467.

SkinNer, R., Cundliffe, E. \& SCHMidT, F. (1983). Site of action of a ribosomal RNA methylase responsible for resistance to erythromycin and other antibiotics. Journal of Biological Chemistry 258, 12702-12706.

Te Riele, H., MiChel, B. \& Ehrlich, S. (1986a). Are single-stranded circles intermediates in plasmid DNA replication? EMBO Journal 5, 631-637.

Te Riele, H., Michel, B. \& Ehrlich, S. (1986b). Single-stranded plasmid DNA in Bacillus subtilis and Staphylococcus aureus. Proceedings of the National Academy of Sciences of the United States of America 83, 2541-2545.

Tinoco, I., Borer, P., Dengler, B., Levine, M., Uhlenbeck, O., Crothers, D. \& Gralla, J. (1973). Improved estimation of secondary structure in ribonucleic acid. Nature New Biology 246, 151-172.

WeISBLUM, B. (1984). Inducible erythromycin resistance in bacteria. British Medical Bulletin 40, 47-53.

Weisblum, B., Graham, M., Gryczan, T. \& Dubnau, D. (1979). Plasmid copy number control: isolation and characterization of high copy-number mutants of plasmid pE194. Journal of Bacteriology 137, 635643.

Yanisch-Perron, C., Vieira, J. \& Messing, J. (1985). New M13 host strains and the complete sequences of M13mp and pUC vectors. Gene 33, 103-119. 